\title{
Migrating humpback whales show no detectable response to whale alarms off Sydney, Australia
}

\author{
Vanessa Pirotta $^{1, *}$, David Slip ${ }^{1,2}$, Ian D. Jonsen ${ }^{1}$, Victor M. Peddemors ${ }^{3}$, \\ Douglas H. Cato ${ }^{4,5}$, Geoffrey Ross ${ }^{6}$, Robert Harcourt ${ }^{1}$ \\ ${ }^{1}$ Department of Biological Sciences, Macquarie University, Sydney, NSW 2109, Australia \\ ${ }^{2}$ Taronga Conservation Society Australia, Bradley's Head Road, Sydney, NSW 2088, Australia \\ ${ }^{3}$ Fisheries NSW, NSW Department of Primary Industries, Sydney Institute of Marine Science, Chowder Bay Road, Sydney, \\ NSW 2088, Australia \\ ${ }^{4}$ Defence Science and Technology Group, Eveleigh, NSW 1430, Australia \\ ${ }^{5}$ School of Geosciences, University of Sydney, NSW 2006, Australia \\ ${ }^{6}$ NSW National Parks \& Wildlife Service, Bridge Street, Sydney, NSW 1481, Australia
}

\begin{abstract}
Migratory Group V (Stock E1) humpback whales Megaptera novaeangliae are at risk of entanglement with fishing gear as they migrate north and south along the east coast of Australia. This study investigated the effectiveness of 2 distinct tones for use as an alarm to acoustically alert whales to fishing gear presence and therefore reduce the chance of entanglement. We compared how whales responded in terms of changes of surface behaviour and changes in direction of travel in response to 2 acoustic tones and when there was no alarm. These 2 acoustic tones were a $5 \mathrm{kHz}$ tone $(5 \mathrm{~s}$ emission interval and $400 \mathrm{~ms}$ emission duration, similar to but higher frequency than the signal from a Future Oceans F3 ${ }^{\mathrm{TM}} 3 \mathrm{kHz}$ Whale Pinger ${ }^{\circledR}$ ) and a 2-2.1 kHz swept tone ( $8 \mathrm{~s}$ emission interval and $1.5 \mathrm{~s}$ emission duration). A total of 108 tracks (focal follows) were collected using a theodolite at Cape Solander, Sydney, Australia, during the whales' 2013 northern migration. Linear mixed effects models were used to determine the effect of the different acoustic tones on whale direction (heading), and behaviour (dive duration and speed). Whales showed no detectable response to either alarm. Whale direction and surfacing behaviour did not differ whether the alarm was 'on' or 'off'. Although the response may have been different if the alarms were attached to fishing gear, the lack of measurable response suggests that the types of tones used are not likely to be effective in alarms intended to reduce entanglement of northward migrating Australian humpback whales.
\end{abstract}

KEY WORDS: Fisheries · Entanglement • Megaptera novaeangliae • Mortality • Bycatch • Acoustic deterrents

\section{INTRODUCTION}

Baleen (Mysticeti) whale entanglement in fishing gear is an expensive, current and potentially serious global problem (Clapham et al. 1999, Read et al. 2006, Cassoff et al. 2011). Interactions between baleen whales and fisheries are likely to increase as whale populations recover in the post-whaling period (Carroll et al. 2011, Gales et al. 2011). Entanglements

${ }^{*}$ Corresponding author: vanessa.pirotta@students.mq.edu.au can inflict a number of life threatening injuries upon whales, including restricted movement, emaciation, rope trauma, infection, tissue damage and death (Moore \& van der Hoop 2012). Unlike commercial whaling, entanglements with fishing gear are an unintentional source of baleen whale mortality (Cassoff et al. 2011, Moore 2014), and pose a serious threat to species such as the Endangered North Atlantic right whale Eubalaena glacialis (Knowlton et al. 2012,

() The authors 2016. Open Access under Creative Commons by Attribution Licence. Use, distribution and reproduction are unrestricted. Authors and original publication must be credited. 
Reeves et al. 2012, van der Hoop et al. 2013). Entanglement has been implicated in injury or death of members of most baleen whale species (IWC 2010), including the Arctic bowhead Balaena mysticetus (Reeves et al. 2012), fin Balaenoptera physalus (Lien 1994), minke B. acutorostrata (Northridge et al. 2010, Song et al. 2010), humpback Megaptera novaeanglia (Lien 1980, Neilson et al. 2009) and southern right whale E. australis (Best et al. 2001). Entanglement in fishing gear may also be a limiting factor in the recovery of threatened baleen whale species such as the Critically Endangered western gray whale Eschrichtius robustus (Bradford et al. 2009).

Measures that have been used to reduce whale entanglements in fishing gear have included modifying fishing equipment, seasonal fishery closures (Knowlton \& Kraus 2001, Kraus et al. 2005), and using acoustic alarms that function to alert whales to the presence of fishing gear (Lien 1980, Lien et al. 1995). A major advantage of using alarms over more active fisheries management is that they have the potential to reduce the risk of entanglement without severely impacting the fishery itself. However, for alarms to be effective in preventing entanglement, whales must notice the sound source and also associate it with nets or lines (Lien et al. 1992).

Acoustic alarms have had mixed success in mitigating entanglement for odontocetes (toothed whales), being most successful in reducing bycatch of harbour porpoises, common dolphins, beaked whales and franciscana in gill nets (Barlow \& Cameron 2003, McPherson 2011, Berg Soto et al. 2013, Dawson et al. 2013). Acoustic alarms have been specifically designed to target the hearing range of the animals they are intended to deter (Ketten 1994). Odontocete acoustic alarms typically produce higher frequency tones $(10 \mathrm{kHz})$ compared with the lower frequency alarms used for the non-echolocating baleen whales (3 kHz).

Since the initial work developing whale alarms (Lien 1980), alarm technology has improved, but until recently there has been little systematic research in situ to test the efficiency of whale alarms in deterring whale entanglement from fishing gear (Jefferson \& Curry 1996, Harcourt et al. 2014). A systematic assessment of the effect of a single moored, commercially available whale alarm (3 kHz Whale Pinger®; with source level specified as $135 \mathrm{~dB} \pm 4 \mathrm{~dB}$ re $1 \mu \mathrm{Pa}$ at $1 \mathrm{~m}$ ) on the movements of migrating east coast Australian humpback whales $M$. novaeangliae found that whales showed no detectable response to the alarm over audible ranges (Harcourt et al. 2014). This suggested that a simple, monotonic, $3 \mathrm{kHz}$ low fre- quency alarm was unlikely to deter migrating humpback whales from approaching fishing gear (Harcourt et al. 2014) and reinforced the need to investigate alternatives.

Migrating humpback whales encounter a range of fishing activities as they travel along the east coast of Australia each year from their high latitude summer feeding grounds to their low latitude breeding grounds (Chittleborough 1965). Several types of fishing equipment can potentially entangle whales along this path, including longlines, gillnets, shark nets and single units like lobster and crab pots (Groom \& Coughran 2012). In New South Wales, entanglements of humpback whales in fishing gear comprise the highest proportion of negative anthropogenic interactions with cetaceans documented between 1970 and 2013 (Lloyd \& Ross 2015). Although the east Australian shark net (bather protection) programs in Queensland and New South Wales currently use whale alarms on their nets, there have been ongoing humpback whale entanglements, some fatal, and this suggests the alarms may not be deterring all whales. These alarms were the same model as that tested by Harcourt et al. (2014), who found no detectable response to the alarms.

Southerly migrating humpback whales in southern Queensland are reported to show a consistent behavioural response to an upsweeping tone from 2$2.1 \mathrm{kHz}$ over $8 \mathrm{~s}$ (Dunlop et al. 2013). The robustness of this response suggested that this tone might potentially provide an effective alarm. Therefore, we assessed whether broadcasting this upswept $2-2.1 \mathrm{kHz}$ tone would alter the path of migrating whales and potentially be useful as an alarm for reducing the chance of entanglement. We also assessed the response to a higher frequency $(5.3 \mathrm{kHz})$ signal with similar temporal characteristics to the $3 \mathrm{kHz}$ Whale Pinger®. This new alarm was moored in the middle of the humpback whale migratory corridor off Sydney, Australia. The aim of the study was to test whether the migratory path of northward migrating whales deviated sufficiently in the presence of either of these alarm tones to reduce the likelihood of whales swimming into the alarm.

\section{MATERIALS AND METHODS}

\section{Study site}

The study was conducted at Cape Solander in Botany Bay National Park, Sydney, Australia (34 01' S, $151^{\circ} 14^{\prime} E_{;}$Fig. 1). Humpback whales were tracked 
a

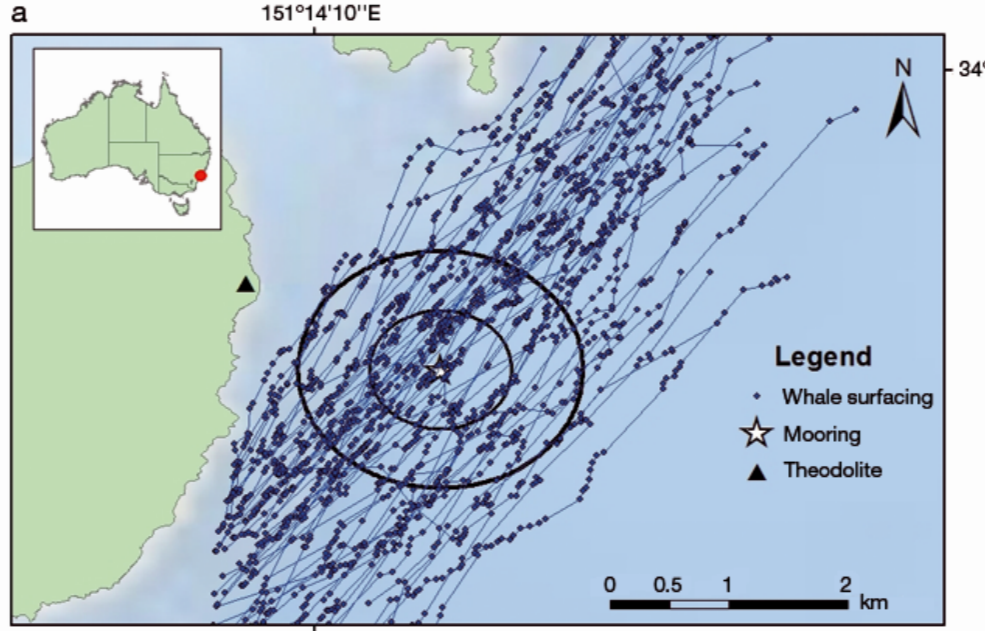

b

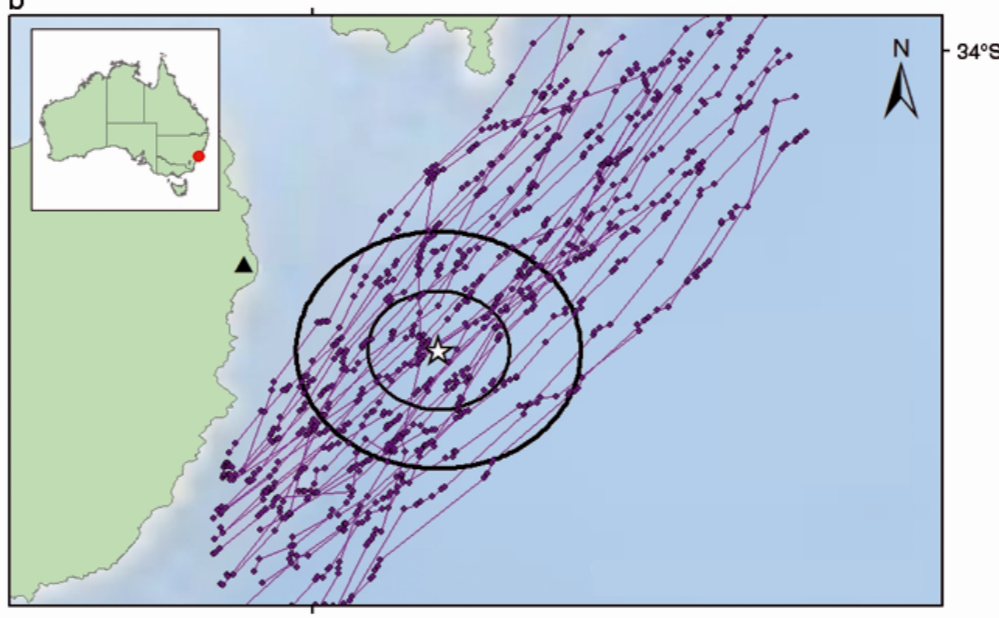

c

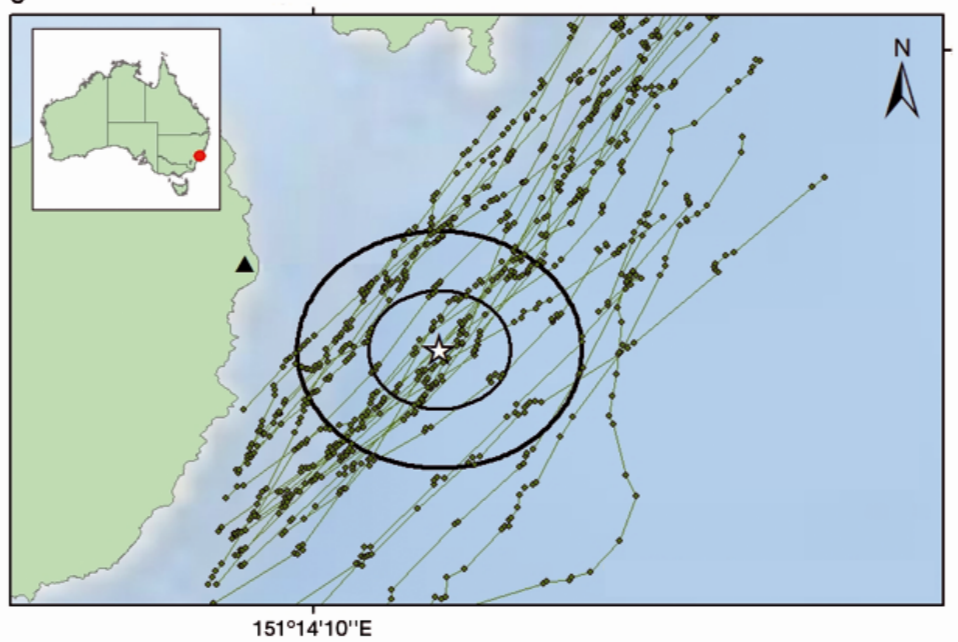

Fig. 1. All tracks that passed within 1000 and $500 \mathrm{~m}$ of the alarm mooring. Whale alarm location indicated by star (depth of $53 \mathrm{~m}$ ). All focal follows that passed through the study site when the alarm was (a) off (control) and focal follows when the alarm emitted either the (b) $5.3 \mathrm{kHz}$ tone or (c) $2-2.1 \mathrm{kHz}$ swept tone. Each dot represents a single whale surfacing along individual focal follows. Triangle represents the location of the theodolite. A black $1000 \mathrm{~m}$ (outer) and $500 \mathrm{~m}$ (inner) radius around the alarm mooring represents the likely acoustic range of detectability from an observation platform that was located $30 \mathrm{~m}$ above sea level and has been used for observing whales during their northern migration for over $18 \mathrm{yr}$.

\section{Whale alarm}

We installed a fixed mooring with a surface float $1.3 \mathrm{~km}$ offshore from the observation platform in $53 \mathrm{~m}$ of water with the prototype whale alarm secured at $5 \mathrm{~m}$ depth. The whale alarm consisted of a rolled aluminum housing enclosing a battery pack, iPod nano ${ }^{\circledR}$, amplifier and loudspeaker (Altronics PA Compression Driver C6115) fitted to the end of the rolled aluminum housing, at a depth of $5 \mathrm{~m}$. This depth was chosen to be similar to that used by the fishing industry to deter whales from entanglement in set nets and lines (Erbe \& McPherson 2012, Harcourt et al. 2014). The whale alarm mooring was anchored in the midpoint of the peak migration route as determined from previous research conducted at the same study site in the years 2006-2008 (Gulesserian et al. 2011).

A randomised playlist was preset on an iPod nano ${ }^{\circledR}$ that played 1 of 2 tones or a control of no tone for $11 \mathrm{~h}$ each day (07:00-16:30 h, daylight hours). The 2 tones were (1) a $2-2.1 \mathrm{kHz}$ swept tone (8 s emission interval and $1.5 \mathrm{~ms}$ emission duration, adapted from Dunlop et al. 2013) and (2) a $5.3 \mathrm{kHz}$ tone of $5 \mathrm{~s}$ emission interval and $400 \mathrm{~ms}$ emission duration. The $5.3 \mathrm{kHz}$ tone was actually the second harmonic of the signal, which had a fundamental frequency at $2.65 \mathrm{kHz}$, but the level was about $10 \mathrm{~dB}$ lower than the $5.3 \mathrm{kHz}$ harmonic, so it was effectively a $5.3 \mathrm{kHz}$ tone.

\section{Data collection}

Data were collected between 28 June 2013 and 4 August 2013 to coincide with the peak of the northern migration (Nicholls et al. 2000, Vang 2002, Gulesserian et al. 2011) using the method described in Harcourt et al. (2014). Whale observations 
were made using the naked eye and $7 \times 50$ magnitude binoculars. All data were recorded using a theodolite set up on the Cape Solander observation deck that stands $30 \mathrm{~m}$ above sea level. A Sokkia DT510A theodolite was connected to a laptop computer running custom written software VADAR $\odot$ (Version 1.51.02 Eric Kneist, University of Newcastle, Australia, http://cyclops-tracker.com/). The theodolite simultaneously measured horizontal and vertical angles to a target whale and fed to a computer that calculated the whale position using VADAR@ $\odot$. The horizontal angle was calibrated using a known reference object, Cape Banks (the headland north of the field site).

At least 2 people constantly scanned to the south for approaching humpback whale groups. A group was defined as either a lone whale or more than one individual. Groups were selected as far south as possible relative to the alarm to allow the approach to be recorded. All whales that passed through the study site were on their annual northern migration, and therefore each focal follow was considered independent. Once a group was seen, a focal animal, distinguishable by the natural variation in markings and dorsal fin shape, was chosen to track within a group. We recorded every surface event for the focal animal, as well as any associated behaviour with every surfacing, from the moment the group was first sighted until it left the study area ( $>4000 \mathrm{~m}$ north of the theodolite) or could no longer be seen. Common causes of poor visibility included intense sunlight and mist. Once a group moved out of the study site, the next southernmost group was selected for tracking (if present). We monitored all vessels using a $15 \mathrm{~min}$ scan of vessel activity (Martin \& Bateson 1998).

Observations were made from dawn until dusk (subject to daylight, usually 06:20-17:20 h Australian Eastern Daylight Time, AEDT) when weather conditions were favourable (no rain and Beaufort of $<4$ ). We recorded weather conditions throughout the day and included: Beaufort, swell, cloud coverage and rain.

\section{Whale alarm recordings}

To estimate the audible range of the prototype whale alarm, we made acoustic recordings as described in Harcourt et al. (2014) at various distances from the alarm. We used a hydrophone (High Tech Inc.) attached to $30 \mathrm{~m}$ of line suspended from a drifting boat and recorded the signal directly onto an M-Audio Micro Track 24/96 Professional 2-Channel Mobile Digital Recorder. The frequency response was $20 \mathrm{~Hz}-20 \mathrm{kHz}$.
We took recordings of the received level from the alarm and the background noise at regular distances along transects - the distance between recording positions was $50 \mathrm{~m}-$ creating a $300 \times 300 \mathrm{~m}$ grid over the position of the alarm. A Garmin GPSMAP® $78 \mathrm{sC}$ GPS to locate the start of each transect line. At the start of a transect line, the boat motor was switched off and the hydrophone was lowered to $30 \mathrm{~m}$ and recording started. We selected transect lines based on wind conditions that would allow drifting along the transect, and once recordings commenced, the boat was allowed to drift over the entire transect. Recordings ceased once the boat had reached the end of the transect line. The boat then motored up to the start of the new transect and the recording process was repeated.

The frequencies of the alarm tones were expected to be audible to humpback whales as they are within the range of humpback whale vocalisations (Ketten 1992, 1997, Au et al. 2006, Dunlop et al. 2008). The threshold of audibility will depend on the received signal to noise ratio, specifically the critical ratio for tonal signals, which is the difference between the level of the tone (i.e. the received level of the alarm) and the noise spectrum level at the same frequency, at the threshold of audibility. Based on the reasoning given by Dunlop et al. (2013) and drawing on measurements of critical ratios for a range of terrestrial and marine mammals (Richardson et al. 1995, Southall et al. 2007), the best estimate of the critical ratio for humpback whales is that it would lie in the range of the ratios for other mammals, i.e. 19-26 dB for $2 \mathrm{kHz}$ and $20-27 \mathrm{~dB}$ for $5.3 \mathrm{kHz}$.

The received signal to noise ratio of a tone was measured as the difference in the level of the tone (corrected for background noise) and the noise spectrum level at the same frequency as the tone. The measurements of the noise were made in the intervals between the transmission of the tone and corrected for the measurement bandwidth to give the spectrum level, i.e. the level in a $1 \mathrm{~Hz}$ band. Measurements of the alarm tones showed that the signal to noise ratios were consistently within the range of critical ratios for distances up to about $500 \mathrm{~m}$ and on some measurements beyond $500 \mathrm{~m}$. The alarm was audible to humans at similar distances. Some examples of the measured signal to noise ratios for the $2 \mathrm{kHz}$ alarm are: $30-32 \mathrm{~dB}$ at $150 \mathrm{~m}, 23 \mathrm{~dB}$ at $500 \mathrm{~m}$, $19-20 \mathrm{~dB}$ at $850 \mathrm{~m}$ and $15-16 \mathrm{~dB}$ at $1.5 \mathrm{~km}$. For the $5.3 \mathrm{kHz}$ alarm, measured levels were $22-23 \mathrm{~dB}$ at $150 \mathrm{~m}, 23 \mathrm{~dB}$ at $500 \mathrm{~m}, 10 \mathrm{~dB}$ at $930 \mathrm{~m}$. Noting that the noise varies with wind speed, the wind conditions during these measurements were chosen to be simi- 
lar to those of the behavioural studies. Noise levels measured from a drifting boat tend to be higher than true background noise because of the additional noise of waves splashing against the boat. Hence, actual noise levels would have been lower than measured and signal to noise ratios would have been higher than measured, so these distance estimates are conservative. However, to ensure that the tones were always within the range of audibility, we limited the analysis to those whale groups that passed within $500 \mathrm{~m}$ of the alarms.

\section{Analysis}

Only focal follows collected via the theodolite that were at least $15 \mathrm{~min}$ in duration, included multiple ( 2 or more) dives, and passed within 1000 and $500 \mathrm{~m}$ of the alarm were included in the analysis. We analysed whale behaviour during focal follows according to 3 response variables: (1) heading (degrees); (2) dive duration (s); and (3) travelling speed $\left(\mathrm{m} \mathrm{s}^{-1}\right)$. We calculated heading as the bearing between consecutive surfacings measured in relation to north. Dive duration was calculated as the time (s) between the last respiration before each dive and the first after that dive. Whales typically remained at the surface respiring a number of times after a dive. To avoid calculating sequential surfacing respirations after a dive, all surfacing events less than $120 \mathrm{~s}$ apart were excluded from the analysis. Travelling speed was measured as the time taken to travel the distance between consecutive sightings $\left(\mathrm{m} \mathrm{s}^{-1}\right)$. To measure the potential effects of the alarm, we assessed whale behaviour between 2 treatments $(2-2.1 \mathrm{kHz}$ tone and $5.3 \mathrm{kHz}$ tone) and a control (no tone).

As we could not observe whale behaviour underwater, these 3 behavioural responses were chosen on the basis of being observable through the methodology used in this study. If the alarm was to have any effect on an individual whale, we tested whether travel speed, dive duration or directional movements differed between the treatment and the control. We used a cosine transformation to account for the circular nature of the heading data and a logit transformation to normalize the cosines of the headings.

Linear mixed-effects models (Pinheiro \& Bates 2000) were used to assess differences between treatments for the 3 response variables. We treated the focal follow as a random effect to account for the repeated measures within individual whales. For each response variable, we compared the Akaike information criterion (AIC) of models with and with- out (i.e. Null models) alarm status as a fixed effect. We also used likelihood ratio (LR) tests to assess whether differences between these model pairs were significant $(\mathrm{p}<0.05)$. All statistical analyses were performed using the nlme library (Pinheiro et al. 2014) in the statistical software package R (R Foundation for Statistical Computing).

\section{RESULTS}

A total of 108 focal follows were recorded over $300 \mathrm{~h}$ of observation. Observations were made for $12 \mathrm{~d}$ while the source was silent (control), $10 \mathrm{~d}$ for the upswept 2-2.1 kHz tone, and $11 \mathrm{~d}$ for the $5.3 \mathrm{kHz}$ tone. Each group was considered independent as whales were on their annual northern migration. For focal follows that passed within $1000 \mathrm{~m}$ of the alarm, $52 \%(\mathrm{n}=57)$ occurred during the control treatment, $27 \%(\mathrm{n}=28)$ occurred during the $2-2 . \mathrm{kHz}$ treatment, and $21 \%(\mathrm{n}=23$ ) occurred during the $5.3 \mathrm{kHz}$ treatment. For focal follows that passed within $500 \mathrm{~m}$ of the alarms, $48 \%(\mathrm{n}=30)$ occurred during the control, $28 \%$ ( $\mathrm{n}=18$ ) occurred during the $2-2.1 \mathrm{kHz}$ treatment, and $24 \%(\mathrm{n}=15)$ occurred during the $5.3 \mathrm{kHz}$ treatment. The surface plots of whale movements under the 2 treatments and the control were visually similar (Fig. 1).

The direction whales were heading did not differ between the control and treatments within both 1000

Table 1. Comparison of linear mixed-effects models that used the Akaike information criterion (AIC) and likelihood ratios (LR) to assess differences in whale response variables among treatments $(2-2.1 \mathrm{kHz}, 5.3 \mathrm{kHz}$ and control) within a $1000 \mathrm{~m}$ radius of the alarm

\begin{tabular}{|lrrrr|}
\hline Response variable & Null AIC & AIC & LR & p-value \\
\hline Downtime (min) & 603.419 & 606.201 & 1.219 & 0.544 \\
Speed $\left(\mathrm{m} \mathrm{s}^{-1}\right)$ & 786.931 & 789.977 & 0.954 & 0.621 \\
Heading $\left({ }^{\circ}\right)$ & 2704.267 & 2707.613 & 0.654 & 0.721 \\
\hline
\end{tabular}

Table 2. Comparison of linear mixed-effects models that used the Akaike information criterion (AIC) and likelihood ratios (LR) to assess differences in whale response variables among treatments $(2-2.1 \mathrm{kHz}, 5.3 \mathrm{kHz}$ and control) within a $500 \mathrm{~m}$ radius of the alarm

\begin{tabular}{|c|c|c|c|c|}
\hline Response variable & Null AIC & AIC & LR & $\mathrm{p}$-value \\
\hline Downtime (min) & 397.086 & 399.909 & 1.177 & 0.555 \\
\hline Speed $\left(\mathrm{m} \mathrm{s}^{-1}\right)$ & 357.515 & 359.289 & 2.227 & 0.329 \\
\hline Heading $\left({ }^{\circ}\right)$ & 1671.231 & 1675.202 & 0.028 & 0.986 \\
\hline
\end{tabular}



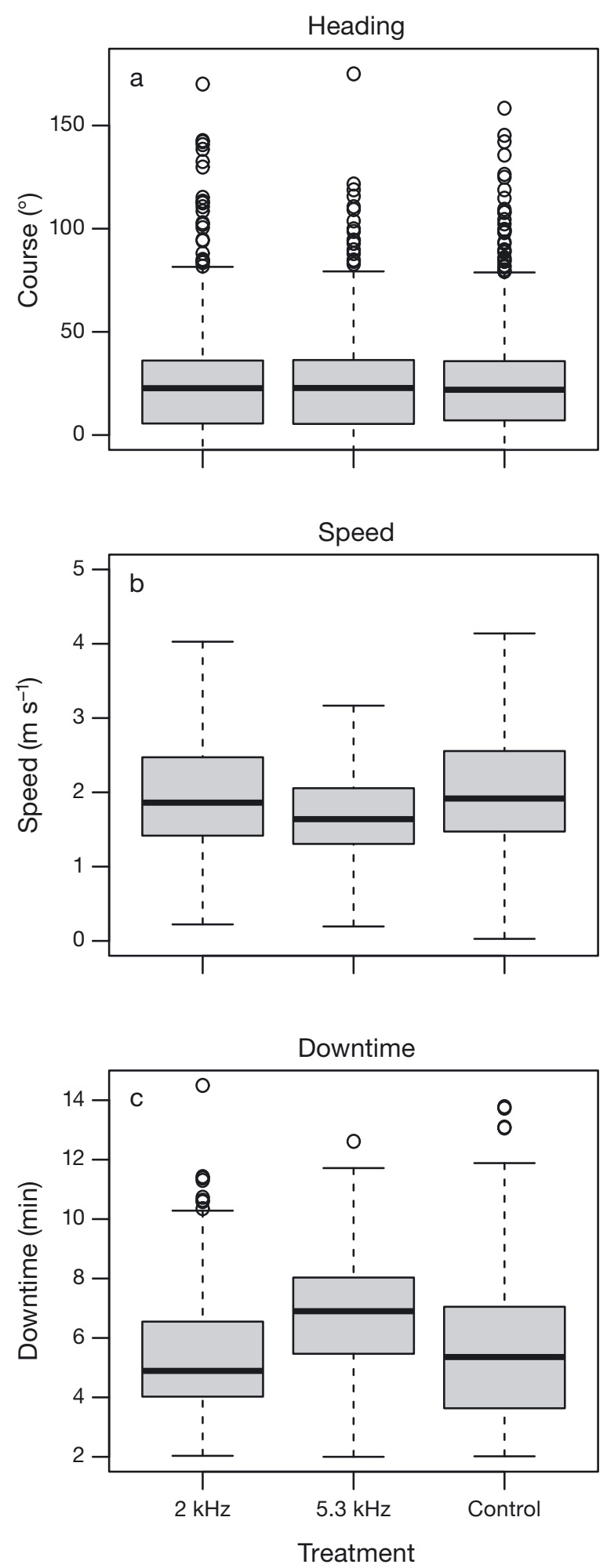

Fig. 2. Boxplots of each response variable for whales that passed within a $500 \mathrm{~m}$ radius of the alarm between treatments (2-2.1 kHz, $5.3 \mathrm{kHz}$ and control): (a) heading, (b) travelling speed and (c) downtime. Grey boxes: inner quartile ranges; black lines: median of each treatment; whiskers: lower and upper quartiles of the data; single dots: outliers and $500 \mathrm{~m}$ of the alarm (Tables 1 \& 2, Fig. 2a). Whales followed a similar northeast path as they travelled through the study site. Collectively, these results suggest that the directionality of whale movements was independent of the alarm. Movements may be most likely influenced by other factors, such as the topography.

Whale speed (Tables $1 \&$ 2, Fig. 2b) and dive duration (downtime) (Tables 1 \& 2, Fig. 2c) did not differ between the alarm treatments and the control within both 1000 and $500 \mathrm{~m}$ of the alarm. The mean speed across both treatments and the control was similar, $2 \mathrm{kHz}: 2 \mathrm{~m} \mathrm{~s}^{-1}\left(\mathrm{SD}=1.08 \mathrm{~m} \mathrm{~s}^{-1}, \mathrm{n}=28\right), 5.3 \mathrm{kHz}: 2 \mathrm{~m}$ $\mathrm{s}^{-1}\left(\mathrm{SD}=1.08 \mathrm{~m} \mathrm{~s}^{-1}, \mathrm{n}=23\right)$ and control: $2 \mathrm{~m} \mathrm{~s}^{-1}(\mathrm{SD}=$ $1.17 \mathrm{~m} \mathrm{~s}^{-1}, \mathrm{n}=57$ ). This suggests that speed and dive duration were not influenced by the alarm.

\section{DISCUSSION}

Baleen whale entanglement in fishing gear is an international problem that is likely to increase with the growth of fishing effort alongside the recovery of some whale populations post-whaling (Read 2008, Pauly 2009). A recent study that tested the effectiveness of a $3 \mathrm{kHz}$ commercial whale alarm that is already widely used on fishing nets found that northward migrating humpback whales showed no detectable behavioural response to the alarm, suggesting that either the tone was too faint in a noisy ocean or that the whales were indifferent to the tone (Harcourt et al. 2014). In the present study we tested the response of humpback whales to different tonal signals, a higher frequency tone $(5.3 \mathrm{kHz})$ and a more complex tone (swept from $2.0-2.1 \mathrm{kHz}$ ) that humpback whales were found to respond to during the southern migration (Dunlop et al. 2013). Even with these differences we could not detect any responses from whales in directionality, speed or dive duration as a result of either alarm being present, consistent with the results of the study by Harcourt et al. (2014).

There may be a number of reasons why whales did not respond to either the swept tone or the higher frequency version of an existing alarm signal. The swept $2 \mathrm{kHz}$ tone was adopted because there were clear and consistent responses reported for southward migrating humpback whales (Dunlop et al. 2013). However, most of the responding whales in that study were females with newborn calves, sometimes accompanied by escorts (Dunlop et al. 2013), whereas in our study the whales were predominantly adults including near-term pregnant females. Whale 
behaviour may differ depending on the direction of migration and the social category. For example, southward migrating mothers may be more cautious and responsive in order to protect their calves in comparison to northerly migrators still anticipating reproduction and competing to mate (Noad \& Cato 2007, Smith et al. 2012). Possibly, whale responses to the alarm used in this study may have been too subtle to detect by means of a theodolite.

As humpback whales move along the east coast of Australia, they are exposed to many different natural and anthropogenic sounds during their migration (Cato \& Bell 1992, Cato \& McCauley 2002, Cato 2010). Whether humpback whales are able to associate the sound of an alarm with a threat is unclear. It is reasonable to assume that whales migrating along the east coast of Australia are accustomed to a wide variety of noises, in which case the alarm sounds may appear simply as another, minor, component of this modified acoustic environment (Dunlop et al. 2010). In addition, ambient noise along the east coast of Australia may also have the potential to mask the alarm's output (Cato \& McCauley 2002, Erbe \& McPherson 2012). To be effective, any acoustic alarm must be functional in noisy areas not just quiet ones. We suggest that lack of audibility was not the problem in our case. Our in situ measurements of the received levels of the alarms and the background ambient indicated that the signal to noise ratios should have been adequate for the alarms to have been consistently audible at distances up to at least $500 \mathrm{~m}$ and beyond $500 \mathrm{~m}$ for some of the time.

If we assume acoustic detectability, it is possible that whales may have been 'alerted' but simply did not deviate away from the alarm. Initial experiments by Lien (Lien 1980, Lien et al. 1990a,b, 1992) demonstrated that in different cases whales could be both attracted and deterred from acoustic devices. In some instances whales slowed and turned in the direction of the sound to investigate, while others turned away from the sound source and increased speed (Lien 1980, Lien et al. 1990a,b, 1992). However, these trials were conducted on humpback whales within feeding areas as opposed to the humpback whales in midmigration tested in our study. Baleen whales devote a large proportion of time and energy each year to migration (Corkeron \& Connor 1999, Silva et al. 2013, Braithwaite et al. 2015). Often these migrations involve competitive breeding or calving, all while moving with direct (or near direct) navigational orientation (Corkeron \& Connor 1999, Horton et al. 2011, Waugh et al. 2012). Unlike migrating humpback whales, foraging humpback whale behaviour in- volves active feeding and searching (Stimpert et al. 2012). Foraging whales may be more mindful to any acoustic presence in comparison to migrating humpback whales (Noad \& Cato 2007, Silva et al. 2013). While we do not know whether the whales were actually detecting the alarm tone, our results suggest even if whales were alerted by the alarm, they did not alter behaviour even when passing within $500 \mathrm{~m}$ of it and simply continued on their northward journey.

Currently there is no single solution to reducing whale entanglement in fishing gear. While acoustic alarms may alert humpback whales to nets in feeding areas (Lien 1980, Lien et al. 1990a,b, 1992), they do not appear to be effective for northerly migrating humpback whales (Harcourt et al. 2014, present study). Approaches to reducing entanglements therefore require a more targeted approach rather than attempting one-size-fits-all. In areas where animals are moving slowly with calves, or feeding, the results of Dunlop et al. (2013) indicate that alarms may still be beneficial even if not foolproof. It is possible that other types of acoustic signals may be more effective as alarms. For example, Götz \& Janik (2010) found that signal rise time had an effect on response of pinnipeds. Further research directions may examine the effect of different types of alarms, the potential of an array of complex alarm acoustics incorporating lower and higher frequency tones, as well as swept and modulated tones, with longer emission durations. However, in areas of directed migration a mixture of management strategies such as fishing gear modifications, e.g. breakaways and sinking ground lines (Moore 2014), or seasonal fishery area closures may be effective. Preventing unintentional mortality of baleen whales (Moore 2014), unacceptable cruelty, prolonged suffering (Moore \& van der Hoop 2012) and loss of fishing gear has widespread interest within the global fishing community, government agencies, NGOs and the scientific community. Future efforts to reduce entanglement should be at the forefront of baleen whale conservation biology research.

Acknowledgements. This research was conducted under the Macquarie University Animal Ethics Committee Animal Research Authority 2012-016 and the NSW Office of Environment and Heritage Scientific Research permit SL 100953. This research was made possible through funding from the Department of Environment, Water, Heritage and the Arts, the Australian Marine Mammal Centre, Australian Antarctic Division, the Commonwealth Environment Research Facilities (CERF) programme, and the Taronga Conservation Science Initiative. Vanessa Pirotta was supported by a Macquarie University Masters of Research scholarship. We 
thank Dr. Simon Northridge, Dr. Peter Corkeron and Prof. Douglas Wartzok for reviewing early drafts of the manuscript. We thank Maryrose Gulesserian, Eric Kneist (author of VADAR), Wayne Reynolds, the Cape Solander Whale Migration Study Volunteers and the Kamay Botany Bay National Park Staff for facilitating the field research. Thank you also to Andrew Boomer for construction of the whale alarm, mooring assemblage, deployment, retrieval and hydrophone testing along with Andrew Irvine, Phil McDowall and Andre Steckenreuter. Finally we thank Geoff McPherson for early consultation regarding the use of cetacean mitigation in fishing gear within Australian waters.

\section{LITERATURE CITED}

Au WWL, Pack AA, Lammers MO, Herman LM, Deakos $\mathrm{MH}$, Andrews K (2006) Acoustic properties of humpback whale songs. J Acoust Soc Am 120:1103-1110

$>$ Barlow J, Cameron GA (2003) Field experiments show that acoustic pingers reduce marine mammal bycatch in the California drift gill net fishery. Mar Mamm Sci 19: 265-283

Berg Soto A, Cagnazzi D, Everingham Y, Parra GJ, Noad M, Marsh H (2013) Acoustic alarms elicit only subtle responses in the behaviour of tropical coastal dolphins in Queensland, Australia. Endang Species Res 20:271-282

Best PB, Peddemors VM, Cockcroft VG, Rice N (2001) Mortalities of right whales and related anthropogenic factors in South African waters, 1963-1998. J Cetacean Res Manag 2:171-176

> Bradford AL, Weller DW, Ivashchenko YV, Burdin AM, Brownell RL Jr (2009) Anthropogenic scarring of western gray whales (Eschrichtius robustus). Mar Mamm Sci 25: 161-175

> Braithwaite JE, Meeuwig JJ, Hipsey MR (2015) Optimal migration energetics of humpback whales and the implications of disturbance. Conserv Physiol 3:cov001, doi: 10.1093/conphys/cov1001

Carroll E, Patenaude N, Alexander A, Steel D and others (2011) Population structure and individual movement of southern right whales around New Zealand and Australia. Mar Ecol Prog Ser 432:257-268

Cassoff RM, Moore KM, McLellan WA, Barco SG, Rotsteins DS, Moore MJ (2011) Lethal entanglement in baleen whales. Dis Aquat Org 96:175-185

Cato DH (2010) The effects of noise on marine animals in the context of their natural acoustic environment. Proceedings of 20th International Congress on Acoustics, ICA, 23-27 August 2010, Sydney, Australia, p 1-8

Cato DH, Bell MJ (1992) Ultrasonic ambient noise in Australian shallow waters at frequencies up to $200 \mathrm{kHz}$. MRL Technical Report MRL-TR-91-23. Materials Research Laboratory, Ascot Vale, Melbourne, p 1-27

Cato DH, McCauley RD (2002) Australian research in ambient sea noise. Acoust Aust 30:13-20

Chittleborough R (1965) Dynamics of two populations of the humpback whale, Megaptera novaeangliae (Borowski). Mar Freshw Res 16:33-128

> Clapham PJ, Young SB, Brownell RL (1999) Baleen whales: conservation issues and the status of the most endangered populations. Mammal Rev 29:37-62

Corkeron PJ, Connor RC (1999) Why do baleen whales migrate? Mar Mamm Sci 15:1228-1245

Dawson SM, Northridge S, Waples D, Read AJ (2013) To ping or not to ping: the use of active acoustic devices in mitigating interactions between small cetaceans and gillnet fisheries. Endang Species Res 19:201-221

> Dunlop RA, Cato DH, Noad MJ (2008) Non-song acoustic communication in migrating humpback whales (Megaptera novaeangliae). Mar Mamm Sci 24:613-629

> Dunlop RA, Cato DH, Noad MJ (2010) Your attention please: Increasing ambient noise levels elicits change in communication behaviour in humpback whales (Megaptera novaeangliae). Proc R Soc B 277:2521-2529

Dunlop RA, Noad MJ, Cato DH, Kniest E, Miller PJO, Smith JN, Stokes MD (2013) Multivariate analysis of behavioural response experiments in humpback whales $(\mathrm{Me}-$ gaptera novaeangliae). J Exp Biol 216:759-770

> Erbe C, McPherson C (2012) Acoustic characterisation of bycatch mitigation pingers on shark control nets in Queensland, Australia. Endang Species Res 19:109-121

Gales N, Bannister JL, Findlay K, Zerbini A, Donovan GP (eds) (2011) Humpback whales: status in the southern hemisphere. J Cetacean Res Manag (Spec Issue) 3:1-317

Götz T, Janik VM (2010) Aversiveness of sounds in phocid seals: psycho-physiological factors, learning processes and motivation. J Exp Biol 213:1536-1548

Groom C, Coughran D (2012) Entanglements of baleen whales off the coast of Western Australia between 1982 and 2010: patterns of occurrence, outcomes and management responses. Pac Conserv Biol 18:203-214

> Gulesserian M, Slip D, Heller G, Harcourt R (2011) Modelling the behaviour state of humpback whales Megaptera novaeangliae in response to vessel presence off Sydney, Australia. Endang Species Res 15:255-264

Harcourt R, Pirotta V, Heller G, Peddemors V, Slip D (2014) A whale alarm fails to deter migrating humpback whales: an empirical test. Endang Species Res 25:35-42

> Horton TW, Holdaway RN, Zerbini AN, Hauser N, Garrigue C, Andriolo A, Clapham PJ (2011) Straight as an arrow: humpback whales swim constant course tracks during long-distance migration. Biol Lett 7:674-679

IWC (International Whaling Commission) (2010) Report of the Scientific Committee, IWC/62/Rep 1 (Inc Annex A-C). Agadir; https://swfsc.noaa.gov/uploadedFiles/Divisions/ PRD/Programs/Photogrammetry/SC\%20Report\% 20\%20 A-C.pdf?n=9220 or https://iwc.int/futuredocs

Jefferson TA, Curry BE (1996) Acoustic methods of reducing or eliminating marine mammal-fishery interactions: Do they work? Ocean Coast Manag 31:41-70

Ketten DR (1992) The cetacean ear: form, frequency, and evolution. In: Thomas JA, Kastelein R, Supin A (eds) Marine mammal sensory systems. Plenum Press, New York, NY, p 53-75

Ketten D (1994) Functional analyses of whale ears: adaptations for underwater hearing. OCEANS'94'Oceans Engineering for Today's Technology and Tomorrow's Preservation Proceedings of Underwater Acoustics. IEEE Proc Underwater Acoustics 1:264-270

- Ketten DR (1997) Structure and function in whale ears. Bioacoustics 8:103-135

Knowlton AR, Kraus SD (2001) Mortality and serious injury of northern right whales (Eubalaena glacialis) in the western North Atlantic Ocean. J Cetacean Res Manag 2: 193-208

Knowlton AR, Hamilton PK, Marx MK, Pettis HM, Kraus SD (2012) Monitoring North Atlantic right whale Eubalaena glacialis entanglement rates: a $30 \mathrm{yr}$ retrospective. Mar Ecol Prog Ser 466:293-302 
Kraus SD, Brown MW, Caswell H, Clark CW and others (2005) North Atlantic right whales in crisis. Science 309: $561-562$

Lien J (1980) Whale collisions with fishing gear in Newfoundland. In: Report to Fisheries \& Oceans, Canada. Memorial University of Newfoundland, St. John's

Lien J (1994) Entrapments of large cetaceans in passive inshore fishing gear in Newfoundland and Labrador (1979-1990). Rep Int Whaling Comm (Spec Issue) 15: 149-157

Lien J, Todd S, Guigne J (1990a) Inferences about perception in large cetaceans, especially humpback whales, from incidental catches in fixed fishing gear, enhancement of nets by 'alarm' devices, and the acoustics of fishing gear. In: Thomas JA, Kastelein RA (eds) Sensory abilities of cetaceans: laboratory and field evidence. Plenum Press, New York, NY, p 347-362

Lien J, Verhulst A, Huntsman T, Jones J, Seton R (1990b) Reactions of humpback whales to novel sounds - curiosity \& conditioning. Report of the Scientific Committee of the International Whaling Commission SC/090/G51

Lien J, Barney W, Todd S, Seton R, Guzzwell J (1992) Effects of adding sounds to cod traps on the probability of collisions by humpback whales. In: Thomas JA, Kastelein RA, Supin AY (eds) Marine mammal sensory systems. Plenum, New York, NY, p 701-708

Lien J, Hood C, Pittman D, Ruel P and others (1995) Field tests of acoustic devices on groundfish gillnets: assessment of effectiveness in reducing harbour porpoise bycatch. In: Kastelein RA, Thomas JA, Nachtigall PE (eds) Sensory systems of aqautic mammals. De Spil Publisher, Woerden, p 1-22

Lloyd HB, Ross GA (2015) Long-term trends in cetacean incidents in New South Wales, Australia. Aust Zool 37: 492-500

Martin P, Bateson P (1998) Measuring behaviour: an introductory guide, Vol 420, 2nd edn. Cambridge University Press, Cambridge

McPherson G (2011) Acoustic methods to mitigate bycatch and depredation by marine mammals on commercial fishing operations in Australian waters: fishermens options. In: Proceedings of ACOUSTICS Conference 2011, Gold Coast, Australia, 2-4 November 2011

Moore MJ (2014) How we all kill whales. ICES J Mar Sci 71 : 760-763

> Moore MJ, van der Hoop JM (2012) The painful side of trap and fixed net fisheries: chronic entanglement of large whales. J Mar Biol 2012:1-4

Neilson JL, Straley JM, Gabriele CM, Hills S (2009) Nonlethal entanglement of humpback whales (Megaptera novaeangliae) in fishing gear in northern Southeast Alaska. J Biogeogr 36:452-464

Nicholls AO, Shaughnessy P, Ross GA, Reynolds W, Briggs SW (2000) Analysis of counts of humpback whales (Megaptera novaeangliae) from Cape Solander, New South Wales. Report to the New South Wales National Parks and Wildlife Service. CSIRO Wildlife and Ecology, Canberra

Noad MJ, Cato DH (2007) Swimming speeds of singing and non-singing humpback whales during migration. Mar

Editorial responsibility: Louise Chilvers, Wellington, New Zealand
Mamm Sci 23:481-495

Northridge S, Cargill A, Coram A, Mandleberg L, Calderan S, Reid R (2010) Entanglement of minke whales in Scottish waters: an investigation into occurrence, causes and mitigation. Final Report to Scottish Government CR/ 2007/49, University of St Andrews, St Andrews

Pauly D (2009) Beyond duplicity and ignorance in global fisheries. Sci Mar 73:215-224

Pinheiro J, Bates D (2000) Mixed-effects models in S and SPLUS. Statistics and Computing Series, Springer, New York, NY

Pinheiro J, Bates D, DebRoy S, Sarkar D, R Core Team (2014) _nlme: linear and nonlinear mixed effects models. R package version 3.1-117. http://CRAN.R-project.org/ package $=$ nlme

Read AJ (2008) The looming crisis: interactions between marine mammals and fisheries. J Mammal 89:541-548

Read AJ, Drinker P, Northridge S (2006) Bycatch of marine mammals in U.S. and global fisheries. Conserv Biol 20: 163-169

Reeves R, Rosa C, George JC, Sheffield G, Moore M (2012) Implications of Arctic industrial growth and strategies to mitigate future vessel and fishing gear impacts on bowhead whales. Mar Policy 36:454-462

Richardson WJ, Greene CR Jr, Malme CI, Thomson DH (1995) Marine mammals and noise. Academic Press, San Diego, CA

> Silva MA, Prieto R, Jonsen I, Baumgartner MF, Santos RS (2013) North Atlantic blue and fin whales suspend their spring migration to forage in middle latitudes: building up energy reserves for the journey? PLoS ONE 8:e76507

Smith JN, Grantham HS, Gales N, Double MC, Noad MJ, Paton D (2012) Identification of humpback whale breeding and calving habitat in the Great Barrier Reef. Mar Ecol Prog Ser 447:259-272

Song KJ, Kim ZG, Zhang CI, Kim YH (2010) Fishing gears involved in entanglements of minke whales (Balaenoptera acutorostrata) in the East Sea of Korea. Mar Mamm Sci 26:282-295

> Southall BL, Bowles AE, Ellison WT, Finneran JJ and others (2007) Marine mammal noise exposure criteria: initial scientific recommendations. Aquat Mamm 33: 411-522

> Stimpert AK, Peavey LE, Friedlaender AS, Nowacek DP (2012) Humpback whale song and foraging behavior on an Antarctic feeding ground. PLoS ONE 7:e51214

> van der Hoop JM, Moore MJ, Barco SG, Cole TVN and others (2013) Assessment of management to mitigate anthropogenic effects on large whales. Conserv Biol 27: 121-133

Vang L (2002) Distribution, abundance and biology of Group V humpback whales Megaptera novaeangliae: a review. The State of Queensland Environmental Protection Agency, Conservation Management Report, August 2002, p 1-20

Waugh CA, Nichols PD, Noad MC, Bengtson Nash S (2012) Lipid and fatty acid profiles of migrating Southern Hemisphere humpback whales Megaptera novaeangliae. Mar Ecol Prog Ser 471:271-281

Submitted: June 15, 2015; Accepted: November 16, 2015 Proofs received from author(s): January 15, 2016 